\title{
Population structure of the ribbed mussel Geukensia demissa in salt marshes in the southern Gulf of St. Lawrence, Canada
}

\author{
Cortney Watt · David J. Garbary · Caroline Longtin
}

Received: 6 October 2009/Revised: 5 August 2010/Accepted: 6 August 2010/Published online: 22 August 2010

(C) Springer-Verlag and AWI 2010

\begin{abstract}
The ribbed mussel, Geukensia demissa, is highly dependent on the cordgrass Spartina alterniflora for amelioration from environmental stress and substrate stabilization. Spartina alterniflora is a foundation species in marshes, and G. demissa is typically associated with cordgrass beds. Marshes in the southern Gulf of St. Lawrence are experiencing erosion and degradation, presumably as a result of increases in sea level, which increases salinity exposure and negatively impacts $S$. alterniflora. The population structure of the ribbed mussel, Geukensia demissa, was studied at nine sites in six estuaries in the southern Gulf of St. Lawrence in Nova Scotia, Canada, where marsh degradation is occurring. Mussel length was used as a proxy for age of $G$. demissa in three salt marsh zones characterized by density and elevation of Spartina alterniflora: (1) a lower zone in which the $S$. alterniflora was dead, but where the basal mat was coherent, (2) a zone of living, but low density S. alterniflora at the margin of the living marsh, and (3) a zone of dense S. alterniflora one to three meters back from the edge. Mussel length was significantly different across the three zones in seven of the nine sites. Mean length decreased as elevation increased, and small mussels (i.e., $1-3 \mathrm{~cm}$ ) were absent at seven sites. The smallest mussels occurred in the dense S. alterniflora zone, higher in the marsh. Mussel length in the two western sites did not differ between zones, and small mussels (i.e., $1-3 \mathrm{~cm}$ ) were present, but rare. The absence of small mussels in seven of the nine sites, and the size frequency
\end{abstract}

Communicated by H.-D. Franke.

C. Watt · D. J. Garbary $(\bowtie) \cdot$ C. Longtin

Department of Biology, St. Francis Xavier University,

P. O. Box 5000, Antigonish, NS B2G 2W5, Canada

e-mail: dgarbary@gmail.com distribution at remaining sites, suggests a lack of recent recruitment and a long-term threat to the survival of G. demissa. Salt marsh degradation and the death of $S$. alterniflora have negatively impacted $G$. demissa recruitment, and population decline is evident.

Keywords Ecosystem engineers - Geukensia demissa . Population structure - Salt marsh erosion - Sea level rise . Spartina alterniflora

\section{Introduction}

Ecosystem engineers are organisms that modify, maintain or create habitat by impacting the availability of resources through physical changes in biotic or abiotic materials (Jones et al. 1994). Autogenic engineers change the environment through their physical structure, while allogenic engineers transform biotic or abiotic material (Jones et al. 1994). These organisms are often the focus of conservation efforts because they are known to positively impact species richness and diversity (Castilla et al. 2004; Bangert and Slobodchikoff 2006; Borthagaray and Carranza 2007; Buse et al. 2008; Bouma et al. 2009; Bravo et al. 2009), and they have cascading impacts on communities (Coleman and Williams 2002). Salt marshes along the northwestern Atlantic exhibit strong zonation of flowering plants. At the lowest marsh elevations, Spartina alterniflora Loisel. dominates, while at higher elevations, other flowering plants including S. patens (Ait.) Muhl., Juncus spp. and $S$. pectinata Link become dominant and successively exclude species beginning with $S$. alterniflora (Bertness 1991; Davis and Browne 1997). These marshes contain two ecosystem engineers that work together to stabilize the marsh substrate. Spartina alterniflora is considered as an 
autogenic ecosystem engineer in marsh ecosystems because it modifies environmental conditions by aerating anoxic sediments (Arenovski and Howes 1992) and reducing flow velocity and water turbidity (Leonard and Luther 1995; Leonard and Croft 2006), as well as stabilizing the marsh substrate and providing attachment sites for other organisms (Altieri et al. 2007). Geukensia demissa (Dillwyn) is a marsh mussel found half embedded in the mud among the rhizomes and roots of $S$. alterniflora (e.g., Bertness 1984; Jost and Helmuth 2007). These mussels are both autogenic and allogenic ecosystem engineers as they enhance nutrient availability for S. alterniflora, bind and protect sediments and inhibit marsh erosion and degradation (Bertness 1984; Jones et al. 1994). These two ecosystem engineers work together in marshes to increase species richness and abundance through a facilitative cascade where $S$. alterniflora is the foundation ecosystem engineer and $G$. demissa is a secondary engineer that further enhances the impacts of S. alterniflora (Altieri et al. 2007). Geukensia demissa abundance and byssal thread attachment strength is significantly reduced when $S$. alterniflora is removed from the marsh (Altieri et al. 2007). Individual and population growth of $G$. demissa decreases with decreased $S$. alterniflora production (Stiven and Kuenzler 1979). Altieri et al. (2007) found S. alterniflora was able to inhabit new areas and successfully establish without the presence of G. demissa; however, $G$. demissa did not flourish without the environmental amelioration provided by $S$. alterniflora through shading and stabilizing the substrate. Furthermore, the mussels are only found in cordgrass beds in marshes in New England; thus, there appears to be a high dependence of G. demissa on S. alterniflora in this area (Altieri et al. 2007).

Despite the importance of these species in maintaining marshes, no study has investigated their relationship in northern marshes. The vast majority of studies on interactions between $S$. alterniflora and $G$. demissa have been conducted in New England (Bertness 1984; Altieri et al. 2007); however, these marshes do not experience the harsh environmental conditions and increased storm frequency that occurs at latitudes further north (Wimmer et al. 2006; Bertness 2007). Marshes along the southern coast of the Gulf of St. Lawrence, Canada are known to be deteriorating. In healthy marshes, there are clear zones due to the distribution of flowering plants at various elevations; however, in the southern Gulf of St. Lawrence, the marsh edge is fringed with a mat of peat where $S$. alterniflora had once flourished, but has subsequently died off, and protruding from these dead mats are G. demissa (Garbary unpublished). The southern Gulf of St. Lawrence experiences greater environmental stress than New England marshes; therefore, we predicted $G$. demissa would exhibit an even greater dependence on $S$. alterniflora and that recruitment of $G$. demissa to the lowest marsh elevations would be inhibited by the lack of living $S$. alterniflora. Our study set out to investigate the general patterns of $G$. demissa distribution across zones of $S$. alterniflora in the deteriorating marshes along the southern coast of the Gulf of St. Lawrence, Canada. We examined the size structure of populations of $G$. demissa across zones of $S$. alterniflora (defined based on the density of S. alterniflora).

\section{Materials and methods}

Size structure of Geukensia demissa was examined at nine sites along the north shore of Nova Scotia, on the Gulf of St. Lawrence in the late summer and fall of 2007 and 2008. Two sites were located in Pomquet, Merigomish and Pugwash Harbours and one site in Cheticamp, Antigonish and Caribou Harbours (Fig. 1, Table 1). All of these harbors are estuaries formed from drowned river valleys (Davis and Browne 1997). Cheticamp, Pomquet, Merigomish, Antigonish and Caribou Harbour are all shallow water systems (mostly 1-5 m) with sand dune barrier beaches and with soft-bottom communities typically dominated by Zostera marina L. Pugwash Harbour is a deeper water channel with no sand dune barrier present. All the estuaries have extensive areas of fringing salt marshes and a tidal amplitude of approximately $1.4 \mathrm{~m}$. The shores have very limited exposure to wave action, and the fetch for the sampling sites varied from 200 to $500 \mathrm{~m}$. Although there is considerable variation in salinity within each estuary, sampling sites we used typically varied from 20 to 28\% (Kim et al. 2004; Garbary et al. 2008).

Within the region of the marsh dominated by $S$. alterniflora, we defined three zones based on its density and elevation (Fig. 2). The first zone consisted of mats of peat

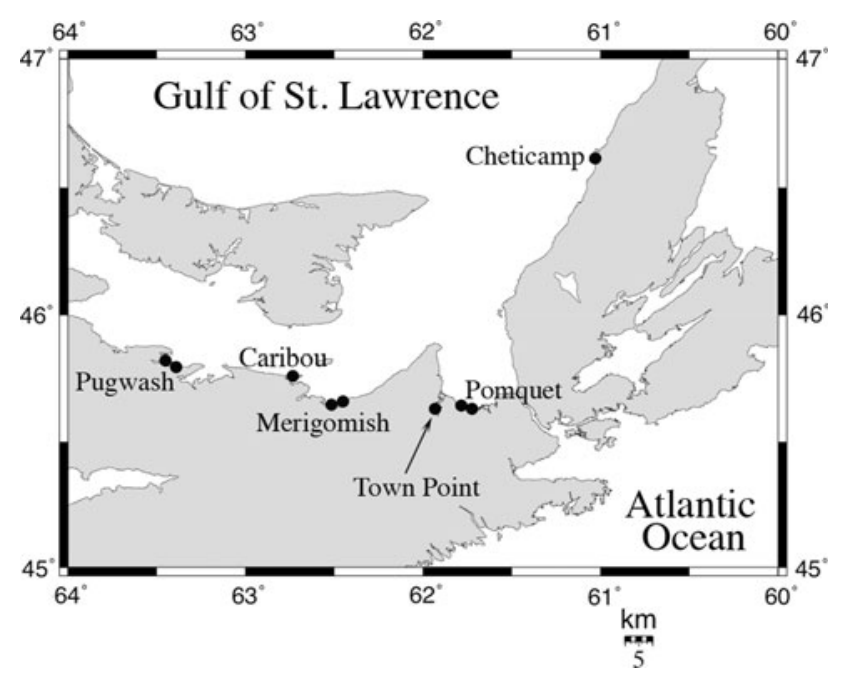

Fig. 1 Map indicating all sites sampled in Nova Scotia, Canada 
Table 1 Estuary, study site with coordinates and the years each study site was sampled or visited

\begin{tabular}{llll}
\hline Estuary & Study site & Longitude/latitude & Dates sampled/visited \\
\hline Cheticamp Harbour & Cheticamp & $61^{\circ} 02^{\prime} 1^{\prime \prime} / 46^{\circ} 36^{\prime} 2^{\prime \prime}$ & August 2008/2009 \\
Pomquet Harbour & Pomquet 1 & $60^{\circ} 50^{\prime} 2^{\prime \prime} / 45^{\circ} 38^{\prime} 9^{\prime \prime}$ & September 2007/visited 2008/2009 \\
& Pomquet 2 & $60^{\circ} 49^{\prime} 4^{\prime \prime} / 45^{\circ} 38^{\prime} 7^{\prime \prime}$ & September 2007/visited 2008/2009 \\
Antigonish Harbour & Town Point & $62^{\circ} 54^{\prime} 0^{\prime \prime} / 45^{\circ} 40^{\prime} 3^{\prime \prime}$ & September 2007/2008/2009 \\
Merigomish Harbour & Merigomish 1 & $62^{\circ} 26^{\prime} 3^{\prime \prime} / 45^{\circ} 37^{\prime} 6^{\prime \prime}$ & October 2007 \\
& Merigomish 2 & $62^{\circ} 25^{\prime} 1^{\prime \prime} / 45^{\circ} 38^{\prime} 1^{\prime \prime}$ & October 2007 \\
Caribou Harbour & Caribou & $62^{\circ} 39^{\prime} 5^{\prime \prime} / 45^{\circ} 44^{\prime} 2^{\prime \prime}$ & October 2007 \\
Pugwash Harbour & Pugwash 1 & $63^{\circ} 39^{\prime} 0^{\prime \prime} / 45^{\circ} 50^{\prime} 6^{\prime \prime}$ & August 2008 \\
& Pugwash 2 & $63^{\circ} 39^{\prime} 5^{\prime \prime} / 45^{\circ} 50^{\prime} 4^{\prime \prime}$ & August 2008 \\
\hline
\end{tabular}

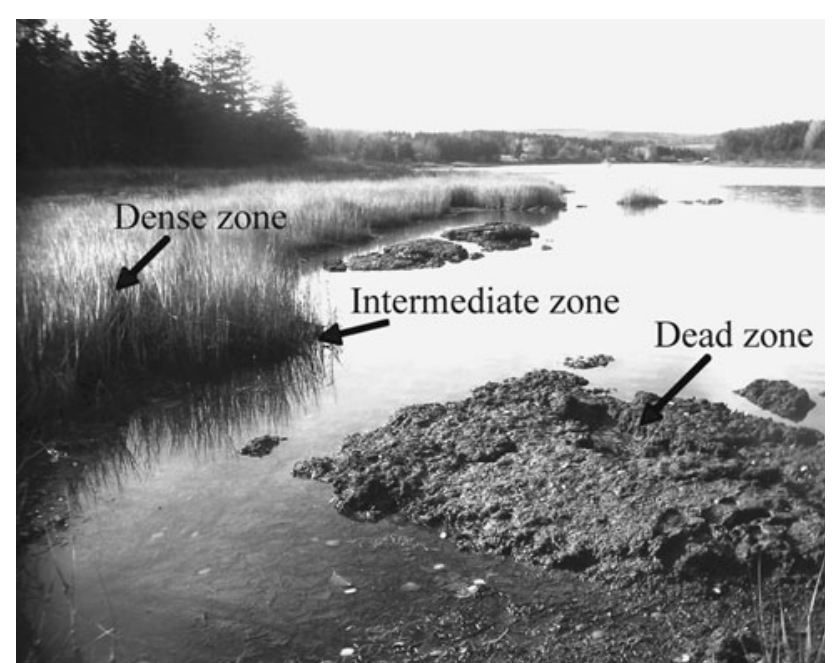

Fig. 2 Portion of salt marsh at Town Point, Antigonish Harbour with arrows indicating the three Spartina alterniflora zones

where S. alterniflora had once grown, but had died and was at the lowest marsh elevations. At some sites, the dead zone was contiguous with the living marsh vegetation; at other sites, the dead mats had become detached and drifted to slightly lower intertidal elevations. The width of this zone ranged from 0.6 to $4.0 \mathrm{~m}$ (average ca. $1.7 \mathrm{~m}$ ), as measured from the widest area where mussels were sampled. At zone margins, the zones were sometimes indistinct and, therefore, $G$. demissa was defined as being in the dead zone if there was no living $S$. alterniflora within $5.0 \mathrm{~cm}$ around the mussel. The 'living' marsh vegetation begins with a region in which S. alterniflora appears healthy, but occurs in relatively low density and was higher in elevation than the dead zone. We refer to this as the intermediate zone. The zone was adjacent to the dead zone but slightly higher in elevation $(\mathrm{ca} .10 \mathrm{~cm})$. Within this zone, there was living $S$. alterniflora; however, it was sparse. The width of this zone across the sites was $1.0-2.8 \mathrm{~m}$ (average ca. $1.7 \mathrm{~m}$ ). Geukensia demissa was defined as being a part of the intermediate zone if it had at least one living $S$. alterniflora shoot within $5.0 \mathrm{~cm}$. The final zone was referred to as the dense S. alterniflora zone, and it was between the intermediate zone and a region of marsh dominated either by Spartina patens or by Juncus gerardii and was at the highest marsh elevation considered. Geukensia demissa in the dense zone was surrounded by $S$. alterniflora on all sides and was often attached to the underground root-rhizome system by byssal threads. The width of this zone across the sites was 1.2-6.4 m (average ca. $2.9 \mathrm{~m}$ ).

The lengths of $150 \mathrm{G}$. demissa were measured per site, 50 from each of the dead, intermediate and dense zones. Geukensia demissa population numbers were low in all sites, and the first 50 mussels encountered during an intensive search, beginning at one edge of the marsh, were measured. The mussels were measured from the anterior to the posterior ends. Although counting internal growth rings provides an accurate measure of age, we chose length as an approximation of age because this method is non-destructive. In addition, previous studies found that length of G. demissa is highly correlated with age (Lutz and Castagna 1980; Brousseau 1984; Bertness and Grosholz 1985). Analysis of external growth bands has also been used to age mussels; however, this procedure is not as accurate because annual rings are not always clearly distinguished from other concentric lines and scars on the shell surface (Brousseau 1984). These rings can be hard to distinguish once the mussel ages and shell erosion occurs. Furthermore, we considered this method too intrusive.

The density of mussels within each zone was determined using a $50 \times 50 \mathrm{~cm}$ quadrat $\left(0.25 \mathrm{~m}^{2}\right)($ Fig. 3). Quadrats were placed on both sides of a five meter transect line within each zone. The number of mussels within the quadrat was counted ( $n=10$ for each zone at each site). Density measurements were only conducted at three sites because the population of $G$. demissa was too small at the other sites $\left(<4\right.$ mussels $\left.\mathrm{m}^{-2}\right)$. However, we do not believe that densities at any of the sites were large enough to cause density-driven effects on recruitment. Mussel density was analyzed in a two-way ANOVA with Site (random; 3 

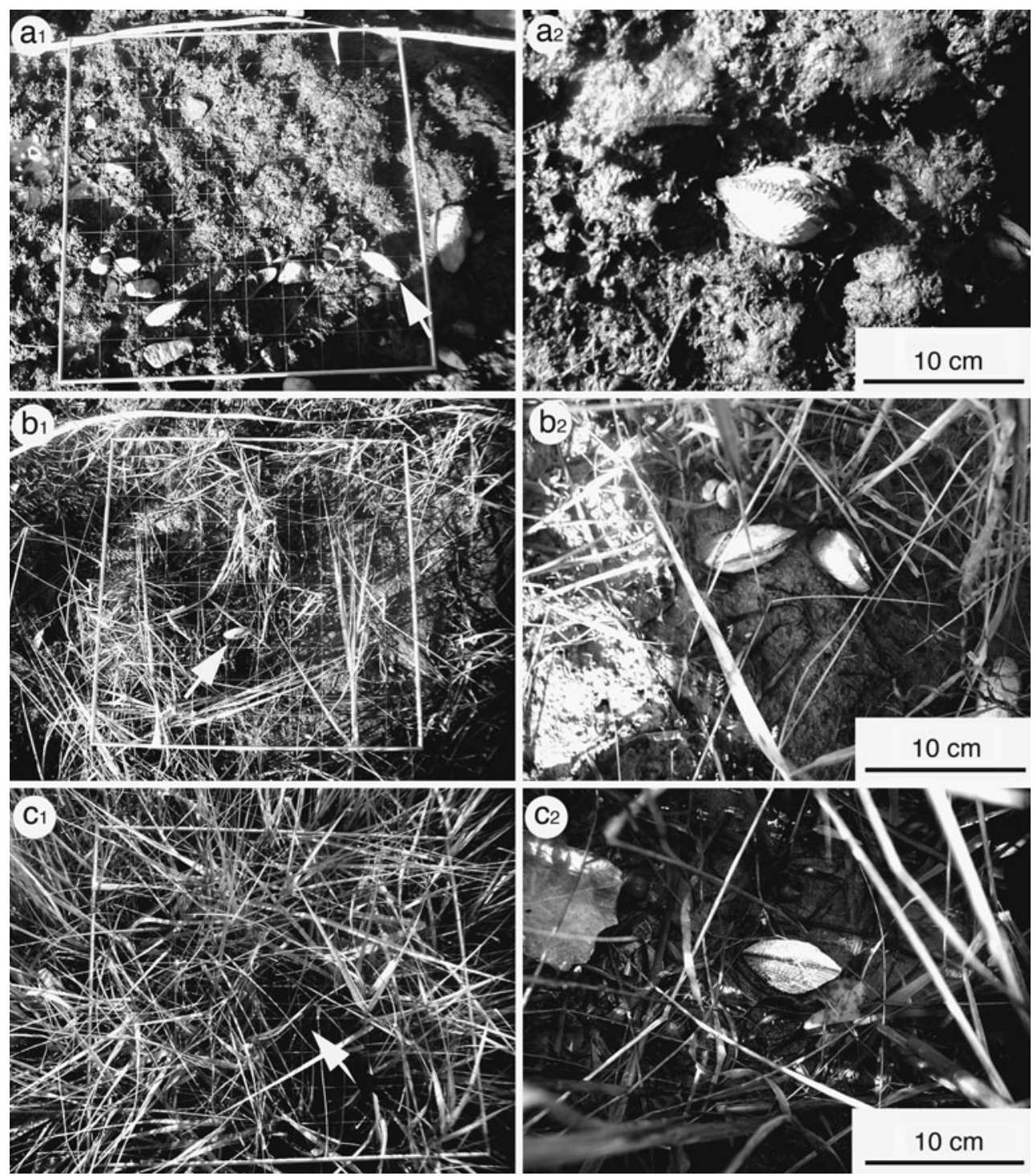

Fig. 3 Photograph of a quadrat on each of the three Spartina alterniflora zones; adjacent photograph indicates Geukensia demissa in each of the zones. Arrows indicate the mussel within the quadrat

that is blown up in $\mathbf{a}_{2}, \mathbf{b}_{2}$ and $\mathbf{c}_{2} . \mathbf{a}_{1}, \mathbf{a}_{2}$ Dead zone, $\mathbf{b}_{1}, \mathbf{b}_{2}$ intermediate zone and $\mathbf{c}_{1}, \mathbf{c}_{2}$ dense zone

levels), Zone (fixed; 3 levels) and the interaction between the two factors (Site * Zone). Tukey's tests were used to determine where these differences occurred. All statistical tests were conducted using JMP for Mac.

Three sediment samples of $20 \times 20 \mathrm{~cm}$ and $10 \mathrm{~cm}$ deep were taken in each zone at Town Point to determine whether there were any small mussels buried in the sediment that would have been missed during sampling. The samples were cut out of the sediment and brought back to the laboratory to be washed through a $0.5-\mathrm{cm}$ mesh sieve.

Mussel length was analyzed in a two-way ANOVA with Site (random; 9 levels) and Zone (fixed; 3 levels) and the interaction between the two factors (Site $*$ Zone). When a significant interaction was detected, simple effects were investigated utilizing one-way ANOVAs at each level of

the other factor (Underwood 1997). For instance, differences among zones were investigated at each site, and significant differences among sites were investigated within each zone (Underwood 1997). When significance was obtained in the ANOVA, multiple comparisons were made using Tukey's honestly significant difference tests. Normality was assessed using normal quantile plots, and homogeneity of variance was tested across all treatment combinations simultaneously using Levene's test.

We returned to the sites in Pomquet and Antigonish Harbours in 2008 and 2009 and to the Cheticamp site in 2009 to observe the G. demissa populations. Fifty $G$. demissa in the intermediate and dense zones were measured at Town Point in 2008 and 2009. There were fewer than 50 mussels in the dead zone; thus, rather than 
disturbing the already small population, the mussels were not measured, but the total number of mussels was recorded. At the Cheticamp site, it was easy to locate 50 mussels in all zones in 2008; however, upon return to the site in 2009 after extensive searching, there were only 15 mussels located in the dense zone. Thus, analyses comparing mussel length at Cheticamp over time were conducted only on the dead and intermediate zones. Populations of $G$. demissa had reduced to the point that it was no longer possible to locate 50 mussels in any of the zones at the sites in Pomquet; thus, no measurements were conducted.

To determine whether mussel length varied over time, length data at Town Point in 2007, 2008 and 2009 were analyzed in a two-way ANOVA with Time (fixed; 3 levels) and Zone (fixed; 2 levels) and the interaction between the two factors (Time * Zone); mussel length at Cheticamp was analyzed in the same fashion but Time had only 2 levels (2008 and 2009). When a significant interaction was detected, simple effects were investigated for each Time utilizing $t$-tests, and ANOVA was utilized for each Zone to determine whether there was a significant difference between sampling times. Normality was assessed using normal quantile plots, and homogeneity of variance was tested across all treatment combinations simultaneously using Levene's test.

\section{Results}

Mussel length data were normally distributed, but failed to meet the homogeneity of variance assumption (Levene's test, $\left.F_{26,1323}=5.7597, P<0.05\right)$, and no transformation resulted in homogenous variances; however, when conducting experiments with multiple treatments and large sample sizes ( $>6$ in each treatment) the ANOVA is considered robust (Box 1953; Underwood 1997). There was a significant difference among sites (ANOVA, $F_{8,1323}=$ 122.8187, $P<0.0001$ ) and zones (ANOVA, $F_{2,1323}=$ 65.5873, $P<0.0001)$, and a significant interaction between site and zone (ANOVA, $F_{16,1323}=6.0863$, $P<0.0001)$. Simple effects on each site revealed that there was no significant difference in mussel length among zones in Cheticamp (ANOVA, $F_{2,147}=2.1682, P=0.1146$ ) or Pugwash 2 (ANOVA, $F_{2,147}=2.1022, \quad P=0.1258$ ); however, in all other sites, there were significant differences among zones $(P<0.05)$ (Fig. 4). Mussel length was greatest in the dead zone and least in the dense zone in all sites where differences occurred (Tukey's test, $P<0.05$ ), except in Pugwash 2 where mussel length was greatest in the dense zone and least in the intermediate zone (Tukey's test, $P<0.05$ ) (Fig. 4). Simple effects on each zone revealed there were significant differences among sites in the dead (ANOVA, $F_{8,441}=67.1825, P<0.0001$ ), intermediate (ANOVA, $F_{8,441}=51.7704, P<0.0001$ ) and dense (ANOVA, $F_{8,441}=21.4245, \quad P<0.0001$ ) $S$. alterniflora zones. In the dead zone, Town Point had the largest mussels, and sites in Pugwash Harbour had the smallest (Tukey's test, $P<0.05$ ) (Fig. 4). Mussel length in the intermediate zone was greatest at Pomquet 2 and least at the sites in Pugwash Harbour (Tukey's test, $P<0.05$ ) (Fig. 4). In the dense zone, mussel length was greatest at Town Point and the sites in Pomquet Harbour and least in
Fig. 4 Mussel length in the three Spartina alterniflora zones at each site. Asterisks indicate significant differences among zones within each site, while different letters indicate significant differences among sites within each zone. Error bars represent standard error; $n=50$

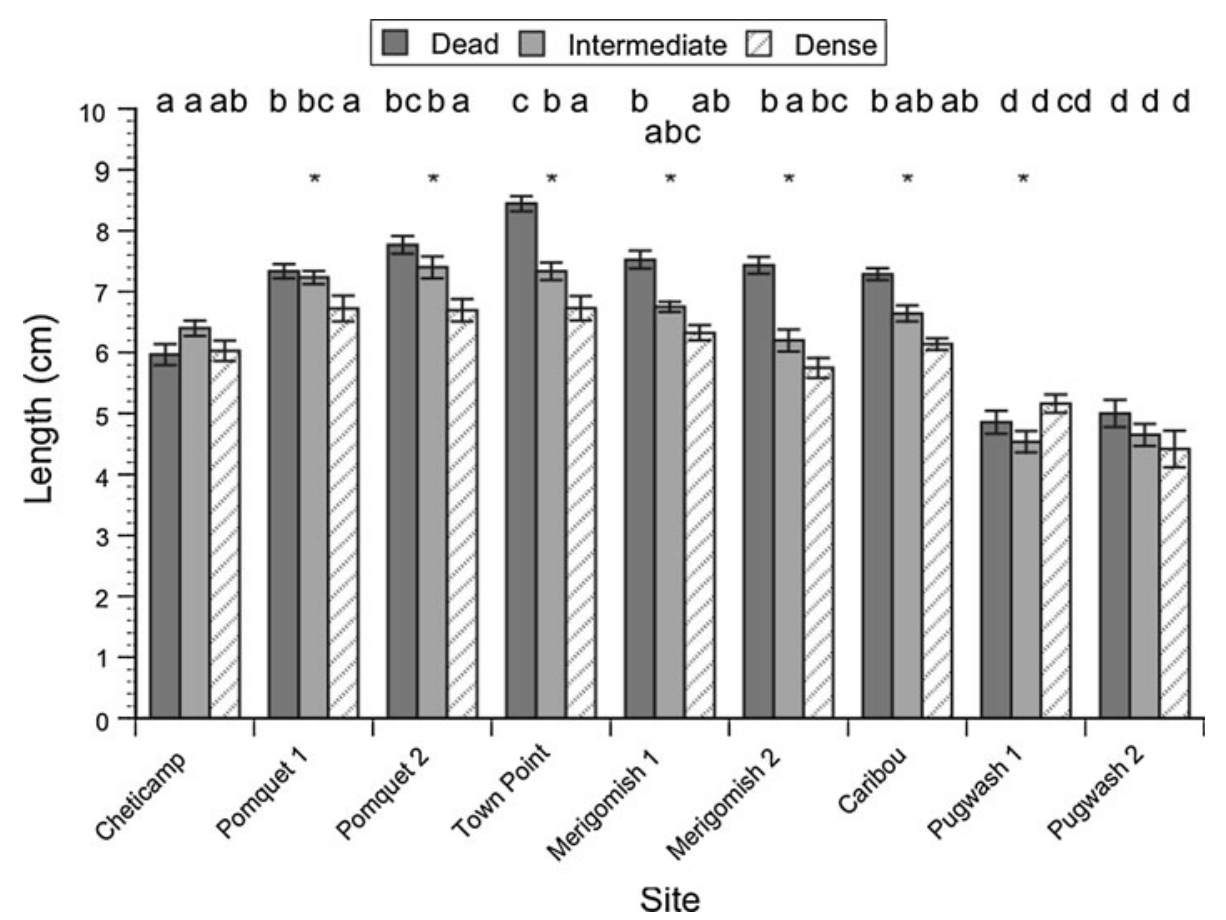




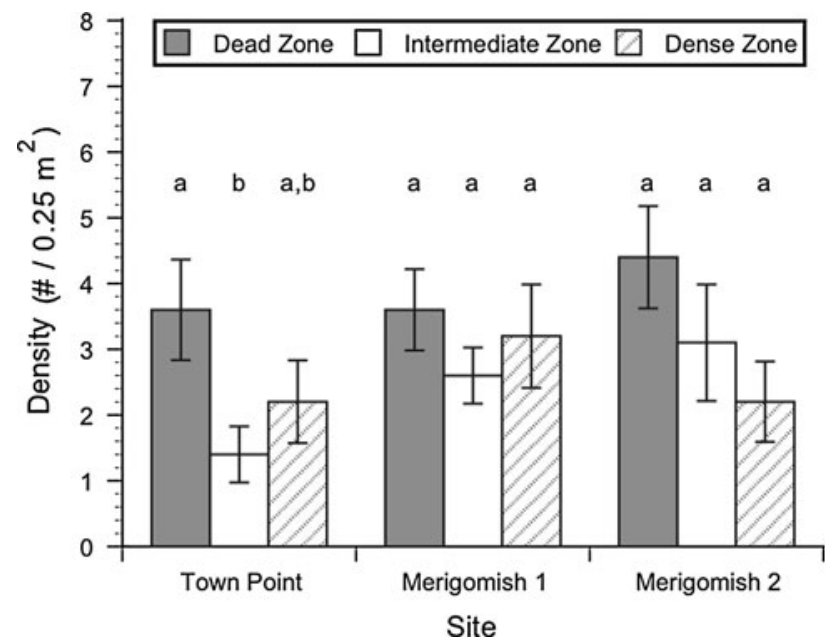

Fig. 5 Mean density (per $0.25 \mathrm{~m}^{-2}$ ) of Geukensia demissa in each of the Spartina alterniflora zones at three sites. Different letters indicate significant differences. Error bars represent standard error; $n=10$

Merigomish 2 and the sites in Pugwash Harbour (Tukey's test, $P<0.05$ ) (Fig. 4).

Mussel density data were normally distributed and met the homogeneity of variance assumption (Levene's test, $\left.F_{2,87}=0.6044, P=0.5487\right)$. There was no significant difference among mussel density across the three sites (ANOVA, $F_{2,81}=1.3608, P=0.2622$ ), and there was no significant interaction between Site and Zone (ANOVA, $\left.F_{2,81}=0.7547, \quad P=0.5578\right)$. However, there was a significant difference between mussel density across the three $S$. alterniflora zones (ANOVA, $F_{2,81}=4.4428, P=$ 0.0148 ), with the highest density occurring in the dead zone (Tukey's test, $P<0.05$ ). However, when mussel density was examined at individual sites, the densities across zones were non-significant at both Merigomish sites and were only significant at Town Point (Fig. 5). At Town Point, density in the dead zone was significantly greater than the intermediate zone (Tukey's test, $P<0.05$ ), but not significantly different from the dense zone (Tukey's test, $P>0.05)$ (Fig. 5).

The sediment samples taken at Town Point revealed no small mussels buried in the sediment. Upon return to Town Point in 2008 and 2009, the dead mats were reduced in size and had been drastically eroded compared to the previous year. At the sites in Pomquet Harbour in 2008 and 2009, the population of Geukensia demissa was extraordinarily small and after intensive searching for $30 \mathrm{~min}$ only 11 mussels were encountered; therefore, there were not sufficient mussels present to measure.

Mussel length was recorded at the Town Point site in Antigonish Harbour in all three S. alterniflora zones in 2007 and in only the intermediate and dense zone in 2008

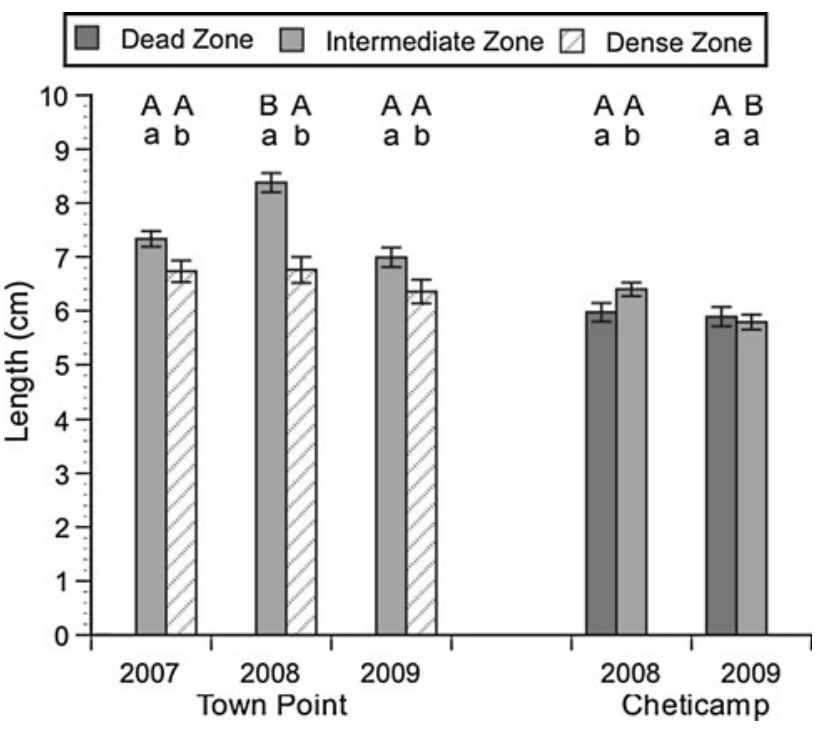

Fig. 6 Mean mussel length across the three Spartina alterniflora zones at Town Point in Antigonish Harbour in 2007 and 2008. Different lowercase letters indicate significant differences between zones within a single year $(P<0.05)$; different capital letters indicate significant differences within a zone between the 2 years sampled $(P<0.05)$. Error bars represent standard error; $n=50$

and 2009; thus analyses over time were only conducted on the intermediate and dense zones. Mussel populations in the dead zone were not measured because the population was reduced to 15 and 13 mussels in 2008 and 2009, respectively, compared to $>50$ in 2007 , therefore we considered sampling detrimental to their survival. Mussel length data over time were normally distributed but failed to meet the homogeneity of variance assumption (Levene's test, $\left.F_{2,297}=5.4953, P=0.0045\right)$; thus, data were arc-sin transformed to meet this assumption (Levene's test, $\left.F_{2,297}=3.1175, P=0.05\right)$. At Town Point, there was a significant difference in mussel length over time (ANOVA, $F_{2,294}=6.6310, P=0.0015$ ) and between zones (ANOVA, $\left.F_{1,294}=30.7523, P<0.0001\right)$, but no significant interaction between the two factors (ANOVA, $F_{2,294}=2.22931$, $P=0.1028$ ). Mussel length was greater in the intermediate $S$. alterniflora zone compared to the dense zone in all three years $(t$-test, $P<0.05)$ (Fig. 6). There was no significant difference in mussel length among years in the dense zone (ANOVA, $F_{2,147}=1.0240, P=0.3617$ ); however, there was a significant difference among years in the intermediate zone (ANOVA, $F_{2,147}=18.4096, P<0.0001$ ) with mussel length being greater in 2008 compared to 2007 or 2009 (Tukey's test, $P<0.05$ ) (Fig. 6).

At the Cheticamp site, mussel length data over time were normally distributed and met the homogeneity of variance assumption (Levene's test, $F_{1,198}=0.3772$, $P=0.5398)$. There was a significant difference in mussel length between the intermediate and dense zones in 2008 
( $t=1.9976, P=0.0485)$, but no significant difference in 2009 ( $t=0.4391, P=0.6616$ ) (Fig. 6). There was no significant difference in mussel length between 2008 and 2009 in the dead $S$. alterniflora zone $(t=0.3211$, $P=0.7489)$, but there was a significant difference in the intermediate zone ( $t=3.2277, P=0.0017$ ) (Fig. 6).

\section{Discussion}

This is the first study to investigate the distribution of G. demissa in marshes in the southern Gulf of St. Lawrence and represent the most northern populations studied to date. Our results show a difference in mussel length across zones of Spartina alterniflora in seven of the nine sites. Although differences in growth rate across the zones could have contributed to our findings of different mussel lengths across the $S$. alterniflora zones, there were no small mussels $(1-3 \mathrm{~cm})$ found in any zone, suggesting a lack of recent recruitment and an unsustainable population in these sites. Potential explanations include the following: (1) we were unable to locate the smallest mussels, (2) recruits are removed by predation, or (3) recruitment could be failing because of declining $S$. alterniflora in the dead mats where these mussels should be prospering.

In the dead and intermediate, zones of S. alterniflora mussels were easy to locate and were clumped together. Mussels in the dense zone were the hardest to locate because they were usually smaller, surrounded by dense $S$. alterniflora, usually solitary, and often buried deeply in the mud with $1 \mathrm{~cm}$ or less protruding. Even though mussels were hardest to locate in the dense zone, this is where we encountered the smallest mussels; thus, we believe if these mussels were located in the dead mats, we would have located them. Furthermore, the sediment samples revealed we were not overlooking very small mussels that may not be distinct in the field.

Increased predation could explain absence of recruits. A conspicuous predator is the invasive green crab, Carcinus maenas, which has had significant impacts on local populations of Mya arenaria (L.) (Floyd and Williams 2004) and may have contributed to the decline of Zostera marina in regional estuaries (Seymour et al. 2002). Although the population of $C$. maenas may be large enough to impact the abundance of young recruits on the marsh, we do not believe this is causing the absence of recruits. In 2007 and 2008 at all sites, in all harbors, populations of Mytilus edulis (L.) have been large with a wide range of mussel sizes present. If $C$. maenas was responsible for the complete absence of recruits, populations of $M$. edulis should also be affected because $C$. maenas is known to feed on $M$. edulis (Breen and Metaxas 2008). Preferential feeding on
G. demissa is unlikely considering its low density in these marshes, and its significantly greater shell thickness compared to M. edulis (Alexander and Dietl 2001). Furthermore, $C$. maenas is also present in the two sites in Pugwash Harbour where at least a few small mussels were found. As a result, we suggest $C$. maenas cannot be solely responsible for the lack of recruits at the other sites.

A final possibility is that mussels are no longer recruiting to the marsh and have not been recruiting to the lowest marsh levels where they would normally be found in high abundances in healthy marshes for some time. Based on the size age distribution presented by Lutz and Castagna (1980), recruitment in seven of the nine sites, even to the dense marsh zone, has not been occurring for at least 2 years and has been extremely limited for at least three additional years. This may be a result of sea level rise. The integrity of salt marshes in Atlantic Canada and elsewhere is being jeopardized by increases in sea level (Najjarr et al. 2000; Hartig et al. 2002; Gehrels et al. 2005; Erwin et al. 2006; Garbary et al. 2008). Effective sea level in the southern Gulf of St. Lawrence has risen over $30 \mathrm{~cm}$ during the twentieth century and is predicted to increase at least another $70 \mathrm{~cm}$ this century (Forbes et al. 2004). Effective sea level includes changes from water level rise and land subsidence (Forbes et al. 2004). This will be exacerbated by even more rapid rates of polar ice melt than was predicted by earlier models (e.g., Velicogna and Wahr 2006). Sea level rise will affect many species, and marsh communities are particularly sensitive because many of the species within these communities cannot withstand high salinities for extended periods. Sea level rise may be the cause of the marsh edge erosion where S. alterniflora grows (Garbary et al. 2008). This may result in decreased recruitment of $G$. demissa because the marsh edge is where the mussels tend to settle (Bertness and Grosholz 1985). Recruitment of G. demissa at the marsh edge has been shown to significantly decrease in experimental plots where $S$. alterniflora has been removed (Bertness and Grosholz 1985). In our case, S. alterniflora has been naturally removed, and recruitment has not been occurring for a few years. Since G. demissa and S. alterniflora have a unique facilitative interaction in marsh systems (Bertness 1984), the reduction of one can result in decreased abundance of the other. The death of $S$. alterniflora at the marsh edge may have resulted in decreases in $G$. demissa recruitment to that area. In addition, the absence of new recruits to the marsh edge, and limited recruitment to the intermediate zone, may result in decreased production of S. alterniflora (Bertness 1984), leading to further decreases in the cordgrass throughout the entire marsh.

A few small mussels $(1.0-3.0 \mathrm{~cm})$ were found, albeit in small abundances, in the two sites located in Pugwash 
Harbour, and mussel size was not significantly greater in the dead zone in these sites. We suggest these populations have experienced recruitment more recently than the other populations. The dead mats at these sites were still contiguous with the living marsh and were smaller in width compared to dead zones at the other sites. The delayed impact in these estuaries may be a result of harbor topography. Accordingly, the channel into Pugwash Harbour is much deeper than the other harbors, and it lacks a sand dune barrier beach, present in the other estuaries. These differences may lead to increases in sedimentation that could compensate for the eroding dead zone. Models presented by Gorand and Monaco (1994) suggest that varying current speeds can have a drastic impact on sedimentation rates. According to Jones (1994), the shape and size of the estuary, as well as the geology of the drainage basin feeding the estuary, are important factors that will affect how sea level rise will impact each estuary. We suggest future studies might evaluate sedimentation and erosion rates in these estuaries to determine how sea level rise is impacting each estuary to provide support for this hypothesis.

Regionally, sea level rise is predicted to increase at a faster rate than we have seen to date (Forbes et al. 2004). Previous studies have found that marsh area on the Atlantic coast of North America is decreasing (Hartig et al. 2002), and marsh surface elevation is not keeping pace with current sea level rise (Erwin et al. 2006). One model suggests that sea level rise will reduce intertidal area, leading to reductions in macro-benthic biomass of up to $12 \%$ with a sea level rise of $0.5 \mathrm{~m}$ (Fujii and Raffaelli 2008). If the $G$. demissa size distribution we obtained in this study is a result of increases in sea level rise, whether or not S. alterniflora and G. demissa can move further from the waters edge fast enough to establish populations prior to water levels becoming prohibitive, remains to be established. Due to the importance of both S. alterniflora and G. demissa in salt marshes in the northern Atlantic, we suggest future studies monitor populations closely and further investigate the association between sea level rise and diminishing cord grass. Jost and Helmuth (2007) suggested that G. demissa and its relationship with S. alterniflora would be a suitable system for monitoring impacts of climate change; this seems particularly the case in the southern Gulf of St. Lawrence.

Acknowledgments We are grateful to Eric Wheeler for field assistance and Ricardo Scrosati for comments on a draft of the manuscript. Cortney Watt was funded through the Canada Research Chair (CRC) and the Natural Sciences and Engineering Research Council of Canada (NSERC) Discovery Grant to R. Scrosati. Research was supported by NSERC grants to DJG.

\section{References}

Alexander RR, Dietl GP (2001) Shell repair frequencies in New Jersey bivalves: a recent baseline for tests of escalation with tertiary, mid-Atlantic congeners. Palaios 16:354-371

Altieri AH, Silliman BR, Bertness MD (2007) Hierarchical organization via a facilitation cascade in intertidal cordgrass bed communities. Am Nat 169:195-206

Arenovski AL, Howes BL (1992) Lacunal allocation and gas transport capacity in the salt marsh grass Spartina alterniflora. Oecologia 90:316-322

Bangert RK, Slobodchikoff CN (2006) Conservation of prairie dog ecosystem engineering may support arthropod beta and gamma diversity. J Arid Environ 67:100-115

Bertness MD (1984) Ribbed mussels and Spartina alterniflora production in a New England salt marsh. Ecology 65:1794-1807

Bertness MD (1991) Zonation of Spartina-patens and Spartinaalterniflora in a New-England salt-marsh. Ecology 72:138-148

Bertness MD (2007) Atlantic shorelines. Natural history and ecology. Princeton University Press, Princeton

Bertness MD, Grosholz E (1985) Population dynamics of the ribbed mussel, Geukensia demissa: the costs and benefits of an aggregated distribution. Oecologia 67:192-204

Borthagaray AI, Carranza A (2007) Mussels as ecosystem engineers: their contribution to species richness in a rocky littoral community. Acta Oecol 31:243-250

Bouma TJ, Ortells V, Ysebaert T (2009) Comparing biodiversity effects among ecosystem engineers of contrasting strength: macrofauna diversity in Zostera noltii and Spartina anglica vegetations. Helgol Mar Res 63:3-18

Box GEP (1953) Non-normality and tests on variances. Biometrika 40:318-335

Bravo LG, Belluire J, Rebollo S (2009) European rabbits as ecosystem engineers: warrens increase lizard density and diversity. Biodivers Conserv 18:869-885

Breen E, Metaxas A (2008) A comparison of predation rates by nonindigenous and indigenous crabs (juvenile Carcinus maenas, juvenile Cancer irroratus, and adult Dyspanopeus sayi) in laboratory and field experiments. Estuar Coasts 31:728-737

Brousseau DJ (1984) Age and growth rate determinations for the Atlantic ribbed mussel, Geukensia demissa Dillwyn (Bivalvia: Mytilidae). Estuaries 7:233-241

Buse J, Ranius R, Assmann T (2008) An endangered longhorn beetle associated with old oaks and its possible role as an ecosystem engineer. Conserv Biol 22:329-337

Castilla JC, Lagos NA, Cerda M (2004) Marine ecosystem engineering by the alien ascidian Pyura praeputialis on a mid-intertidal rocky shore. Mar Ecol Prog Ser 268:119-130

Coleman FC, Williams SL (2002) Overexploiting marine ecosystem engineers: potential consequences for biodiversity. Trends Ecol Evol 17:40-44

Davis DS, Browne S (eds) (1997) The natural history of Nova Scotia, vol 1. Topics and habitats. Nimbus Publishing and Nova Scotia Provincial Museum Halifax, Halifax

Erwin RM, Cahoon DR, Prosser DJ, Sanders GM, Hensel P (2006) Surface elevation dynamics in vegetated Spartina marshes versus unvegetated tidal ponds along the mid-Atlantic coast, USA, with implications to waterbirds. Estuar Coasts 29:96-106

Floyd T, Williams J (2004) Impact of green crab (Carcinus maenas L.) predation on a population of soft-shell clams (Mya arenaria $\mathrm{L}$.) in the southern Gulf of St. Lawrence. J Shellfish Res 23:457-462

Forbes DL, Parkes GS, Manson GK, Ketch LA (2004) Storms and shoreline retreat in the southern Gulf of St. Lawrence. Mar Geol 210:169-204 
Fujii T, Raffaelli D (2008) Sea-level rise, expected environmental changes and responses of intertidal benthic macrofauna in the Humber estuary, UK. Mar Ecol Prog Ser 371:23-35

Garbary DJ, Miller AG, Scrosati R, Kim KY, Schofield WB (2008) Distribution and salinity tolerance of intertidal mosses from Nova Scotian salt marshes. Bryologist 111:282-291

Gehrels WR, Kirby JR, Prokoph A, Newnham RM, Achterberg EP, Evans H, Black S, Scott DB (2005) Onset of recent rapid sealevel rise in the western Atlantic Ocean. Quart Sci Rev 24:2083-2100

Gorand D, Monaco A (1994) Modeling of the sedimentation of marine particles in laminar flow. Application to the continental margind. J Mar Syst 4:441-452

Hartig EK, Gornitz V, Kolker A, Mushacke F, Fallon D (2002) Anthropogenic and climate-change impacts on salt marshes of Jamaica Bay, New York City. Wetlands 22:71-89

Jones G (1994) Global warming, sea level change and the impact on estuaries. Mar Poll Bull 28:7-14

Jones CG, Lawton JH, Shachak M (1994) Organisms as ecosystem engineers. Oikos 69:373-386

Jost J, Helmuth B (2007) Morphological and ecological determinants of body temperature of Geukensia demissa, the Atlantic ribbed mussel, and their effects on mussel mortality. Biol Bull 213:141-151

Kim KY, Garbary DJ, McLachlan JL (2004) Phytoplankton dynamics in Pomquet Harbour, Nova Scotia: a lagoon in the southern Gulf of St Lawrence. Phycologia 43:311-328

Leonard LA, Croft AL (2006) The effect of standing biomass on flow velocity and turbulence in Spartina alterniflora canopies. Estuar Coast Shelf S 69:325-336
Leonard LA, Luther ME (1995) Flow hydrodynamics in tidal marsh canopies. Limnol Oceanogr 40:1474-1484

Lutz RA, Castagna M (1980) Age composition and growth rate of a mussel (Geukensia demissa) population in a Virginia salt marsh. J Mollus Stud 46:106-115

Najjarr RG, Walker HA, Anderson PJ, Barron EJ, Bord R, Gibson JR, Kennedy VS, Knight CG, Megonigal JP, O'Connor RE, Polsky CD, Psuty NP, Richards BA, Sorenson LG, Steele EM, Swanson RS (2000) The potential impacts of climate change on the midAtlantic coastal region. Clim Res 14:219-233

Seymour NR, Miller AG, Garbary DJ (2002) Decline of Canada geese (Branta canadensis) and common goldeneye (Bucephala clangula) associated with a collapse of eelgrass (Zostera marina) in a Nova Scotia estuary. Helgol Mar Res 56:198-202

Stiven AE, Kuenzler EJ (1979) The response of two salt marsh molluscs, Littorina irrorata and Geukensia demissa, to field manipulations of density and Spartina litter. Ecol Monogr 49:151-171

Underwood AJ (1997) Experiments in ecology: their logical design and interpretation using analysis of variance. Cambridge University Press, Cambridge

Velicogna I, Wahr J (2006) Acceleration of Greenland ice mass loss in spring 2004. Nature 443:329-331

Wimmer W, Challenor P, Retzler C (2006) Extreme wave heights in the North Atlantic from altimeter data. Renew Energy $31: 241-248$ 